\title{
LANDFILL MINING INTERVENTION ON MUNICIPAL SOLID WASTE SITES
}

\author{
MAURIZIO BUCCELLA ${ }^{1}$, ELPIDIO MAISTO ${ }^{2}$, GIOVANNI PERILLO $^{3}$, \\ GIOVANNI SOLINO ${ }^{4} \&$ AUGUSTO ZIPPO ${ }^{2}$ \\ ${ }^{1}$ Consorzio di Bacino dei Comuni Salerno 2, Italy \\ ${ }^{2}$ Gisec SpA, Italy \\ ${ }^{3}$ Wessex Institute of Technology, UK \\ ${ }^{4}$ Settore Ambiente, Italy
}

\begin{abstract}
Landfill mining (LFM) is an intervention on existing landfill sites aimed at recovering volumes, in order to make them available for a new use, and to standardize the same sites according to new safety criteria in compliance with the new technical and environmental regulations. This paper analyses the environmental impact issues related to the LFM project designed for two landfills located in San Tammaro, in the Province of Caserta, Italy. The first (called Maruzzella 1), has an area of about 45,000 square meters and it was used for urban solid waste from 1996-1998, for a total volume of about 500,000 cubic meters. The second (called Maruzzella 2), located adjacent to the first, has an area of about 55,000 square meters and it was used for urban solid waste from 1998-2000, for a total volume of about 700,000 cubic meters. Through the complete removal of the waste deposit inside the landfill body it has made it possible to achieve some very important results: 1 . Action of the environmental impact connected with the presence of landfills by removing of the entire amount of waste and the subsequent inerting of dangerous fractions; and 2 . The recovery of the materials present in the landfill: the clusters of waste, that would otherwise be left sine die inside old landfills representing a continuous threat to the environment, are instead valued with consequent obtaining of economic benefits. In fact, more than $70 \%$ of the soil contained in the old landfill was recovered and was reused on site and more than $80 \%$ of inert materials deriving from construction and demolition has been recovered and started for re-use activities.
\end{abstract}

Keywords: landfill, recovery, environmental impact.

\section{INTRODUCTION}

The intervention of construction of the San Tammaro-San Maria La Fossa Technological Pole was born with the interinstitutional agreement of 4 January 2011, between the Minister of the Environment and the Protection of Land and Sea, the Undersecretary of State to the Presidency of the Council of Ministers, the President of the Campania Region, the Presidents of the Provincial Administrations of Naples and of Caserta.

The primary objective of the Technological Pole is to carry out environmental restoration actions in the area between the municipalities of San Tammaro and Santa Maria La Fossa (CE). In the Technological Pole area there are several sites and landfills (Fig. 1), including the Maruzzella I and II dumps (Fig. 2).

As part of the implementation of this Technological Pole, it was envisaged to recover the waste collected in the Maruzzella I and II landfills with the landfill mining (LFM) technique.

Landfill mining [1]-[3] represents a technology of intervention on the existing landfills that consists in the recovery of resources from the latter. Although the intervention is normally fundamentally aimed at recovering old volumes of existing landfills, both to make them available for a new use and to standardize the landfill in question with new safety criteria in compliance with the new technical and environmental regulations after the activation of the itself, through landfill mining it is possible, based on the type of landfill on which the intervention is carried out, to obtain benefits in terms of: 


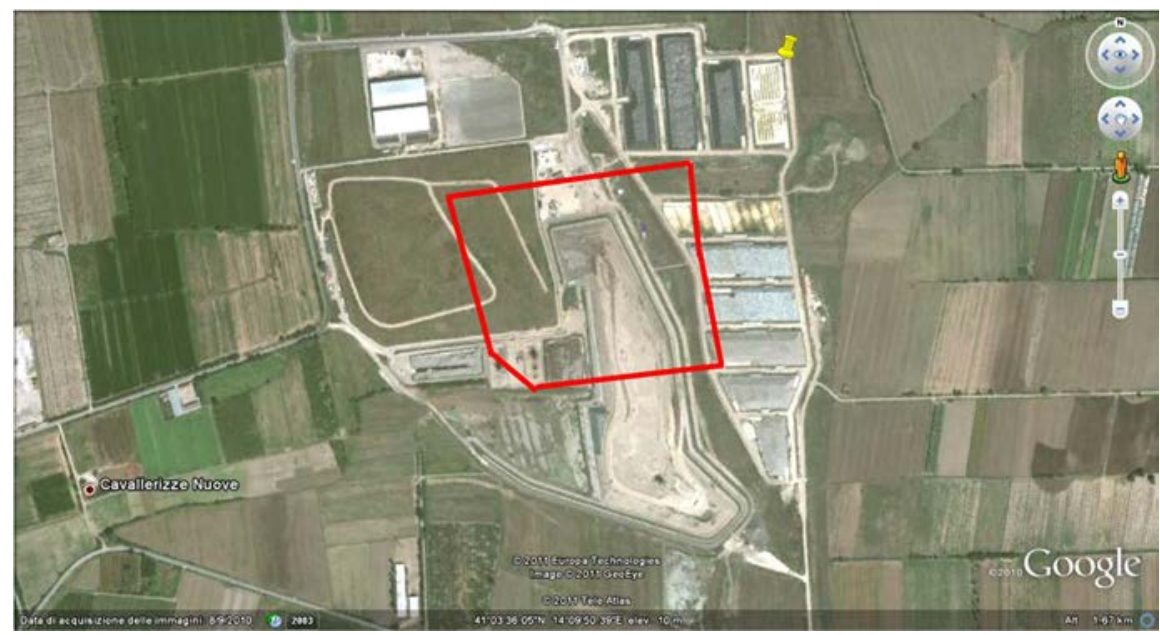

Figure 1: Satellite view of the Technological Pole area.

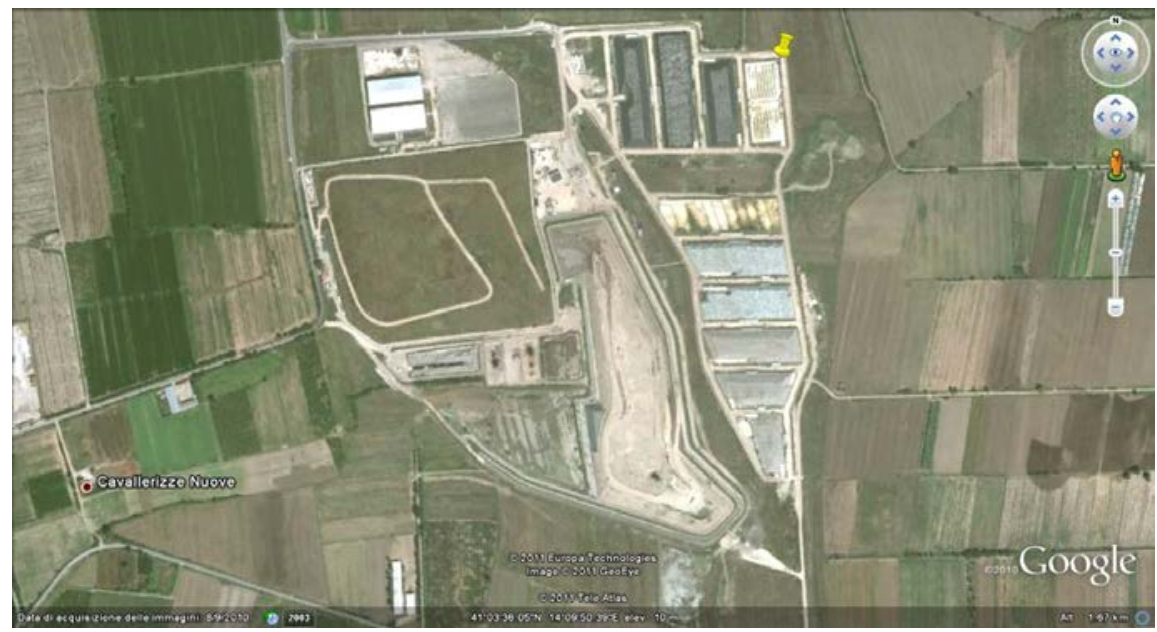

Figure 2: Satellite view landfills of Maruzzella 1 and 2 (San Tammaro, CE).

- Recovery of materials.

- Energy recovery.

- Soil recovery.

Through the complete removal of the waste deposit inside the landfill body it is possible to pursue one or more of the following objectives:

Zeroing of the environmental impact connected with the presence of landfills created and/or managed not in compliance with the law: the removal of the entire amount of waste and the subsequent inertization of dangerous fractions allows a total and definitive resolution of the problem. 
Recovery of materials in the landfill: the waste piles that would otherwise be left sine die in old landfills, representing a continuous threat to the environment are instead valued with consequent economic benefits [2], [4].

Recovery of energy contained in said materials: in analogy with what is indicated in the previous point some recovered materials can be subjected to energy recovery [5].

Restoration of environmental quality: in the case where the landfill area is of particular territorial interest, one can think of the recovery of this area to be allocated to different functional development [5], [6].

Recovery of useful volumetric crowding: the removal of waste and the subsequent treatment can be aimed at relocating a smaller volume of residues at the same site, made compliant with today's environmental regulations.

\section{INTERVENTION AREA}

The Maruzzella 1 landfill is mainly developed in relief with basal plan made with an excavation in depth of 3.00 meters and surface area of about 45,000 square meters; in it, urban solid waste was conferred from 1996 to 1998, for a total volume of about 500,000 cubic meters.

The Maruzzella 2 landfill, located in the south and adjacent to the Maruzzella 1 landfill, is mainly developed in relief with basal plan made with an excavation depth of 2.00 meters and surface area of about 55,000 square meters; in it, urban solid waste was conferred from 1998 to 2000 , for a total volume of about 700,000 cubic meters.

The above mentioned landfills were built in contiguous areas and, over time, have approached to the point of seeming a whole because of the continuous contributions of urban solid waste.

The Maruzzella storage/transfer site, area of about 164,000 square meters and 2,300 m perimeter, is adjacent to the Maruzzella III landfill. In the past, this site has been used as an exclusive service for the temporary storage of undifferentiated waste (CER code 20.03.01) and for chopped waste packed in bales, produced in the regional selection plants (CER code 19.12.12). The project of this site has foreseen the realization of 5 pitches (numbers $2,3 \mathrm{~b}, 8$, 9 and 10) for the storage of waste with the CER code 20.03.01, of 4 pitches (numbers $3 a, 5$, 6 and 7) for the storage of waste with CER 19.12.12. and of 1 pitch (n.3c) adjacent to the pitch $3 \mathrm{~b}$ for the bio stabilization operation of the wet fraction of municipal waste, the latter never used for this purpose.

At the end of the state of emergency, which occurred with the law 26 of 2010, as a result of various measures, it has come to the complete emptying of the pitches from the stored waste, thus returning to the site its function of "provisional".

With regard to the recovery of the area, from the storage site in question, mostly composed of plots already equipped with urbanization works, it is indeed possible to obtain, with very simple procedures, a space equipped to accommodate plants for treatment, recovery and/or recycling of waste.

\section{DESCRIPTION OF THE INTERVENTION}

Based on the results of the fact-finding investigations, taking into account the most appropriate reclamation and recovery techniques for an old landfill, with the primary objective being environmental sustainability and the redevelopment of the entire Maruzzella area of the Municipality of San Tammaro (CE), the design solution involves the recovery of the Maruzzella I and II landfills through the use of the landfill mining technique. The choice made is also justified by the possibility of having an additional volume available for the 
shedding of new waste coming from the STIR of S. Maria CV (CE) (stabilized chopped wet fraction-CER 19.05.01 and 19.05.03) and of superior quality compared to waste abandoned in the past (as it is) in old landfills. This solution will allow, in addition to the recovery of waste currently present in old landfills, the reconstruction of the same with the advantages of using technology and construction materials of quality and durability superior to those originally used for the construction of landfills Maruzzella I and II.

The intervention includes the use of the Maruzzella I and II landfills also of the adjacent platforms.

\section{OPERATIONAL PHASES}

\subsection{Pre-treatment with forced area}

Preliminary in situ aeration of the landfill, with the simultaneous extraction of the percolate from the same wells used for the insufflation/aspiration is of fundamental importance [6], [7]. The oxygen contained in the air that is insufflated with the aeration in situ creates conditions suitable to modify, from anaerobic to aerobic, the conversion process of the biodegradable organic substance contained in the waste. The organic carbon therefore, instead of being converted into methane, carbon dioxide and smelly-reduced compounds (hydrogen sulphide, mercaptans, indole, box, amines, etc.) is transformed into carbon dioxide, water and oxidized substances (nitrates, phosphates, sulfates, etc.). Aerobic metabolism is also favored from an energy point of view compared to anaerobic one; involves an increase in temperature (similar to that in the composting) and a significantly higher degradation rate. Stabilization, among other things, makes the whole cluster more stable.

Therefore, to reduce the formation of malodorous compounds and increase safety during excavation operations, a forced ventilation system will be implemented, using the existing wells, according to the following units and the diagram in Fig. 3.

1. Ventilation wells;

2. Suction wells;

3. Monitoring wells;

4. Insufflation and suction unit;

5. Plant command and control station;

6. Biofiltration system for the treatment of aspirated gas;

7. Percolated percolation system.

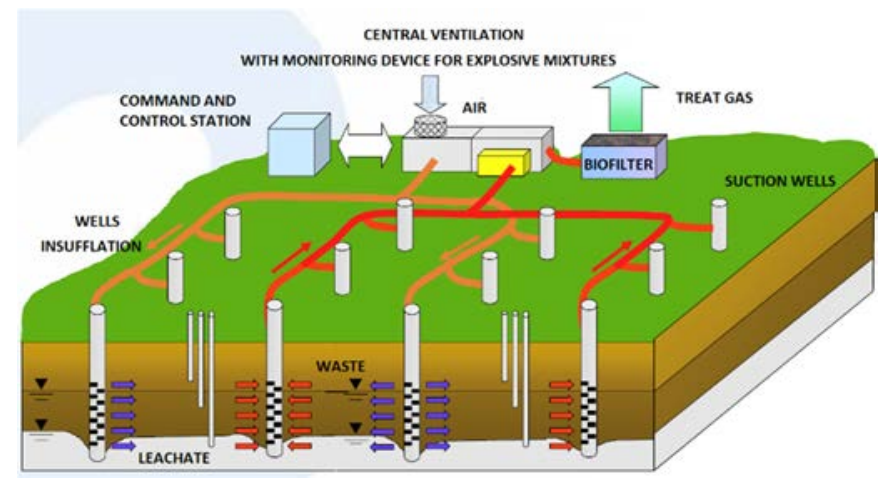

Figure 3: Landfill stabilization scheme. 


\subsection{Preparation of excavation area and material removing}

For the excavation operations the area will be divided into regular modules of 5,000 cubic meters of the size of $20 \mathrm{~m} \times 50 \mathrm{~m}$ approximately with height of about $5 \mathrm{~m}$, intended as macroareas on which to carry out the excavation, in order to plan the removal operations waste and contain leachate production due to eventual rainwater within government areas. To this end, the excavation face will be covered with suitable waterproof sheets. The excavation sequence of the intervention modules and the direction were chosen in relation to the logistic arrangement of the plants and the temporary storage areas of the excavated materials.

The excavation process will be carried out, using mechanical means (using techniques similar to those used in landfill operations). In this phase, excavators or front loader vehicles will be used through which the waste will be extracted from the landfill lot.

During the execution of the work, however, monitoring will be performed to evaluate the personal exposure of the operators to the identified chemical and biological agents and to the dust produced by the handling of waste.

Figs 4(a) and 4(b) show the area during the excavation operations.

The operational excavation procedures will concern 3 flows (Fig. 5):

Flow 1: "Clean" soil deriving from the stratigraphic excavation of the final surface covering of the landfill and lateral banks.

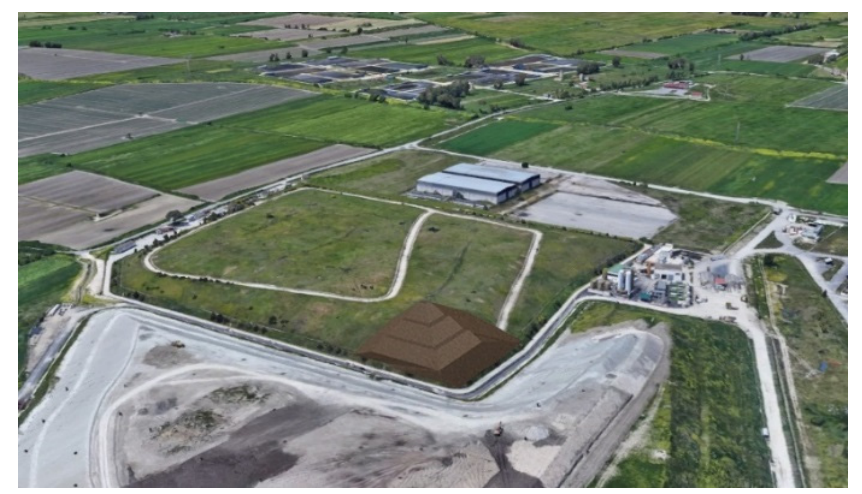

(a)

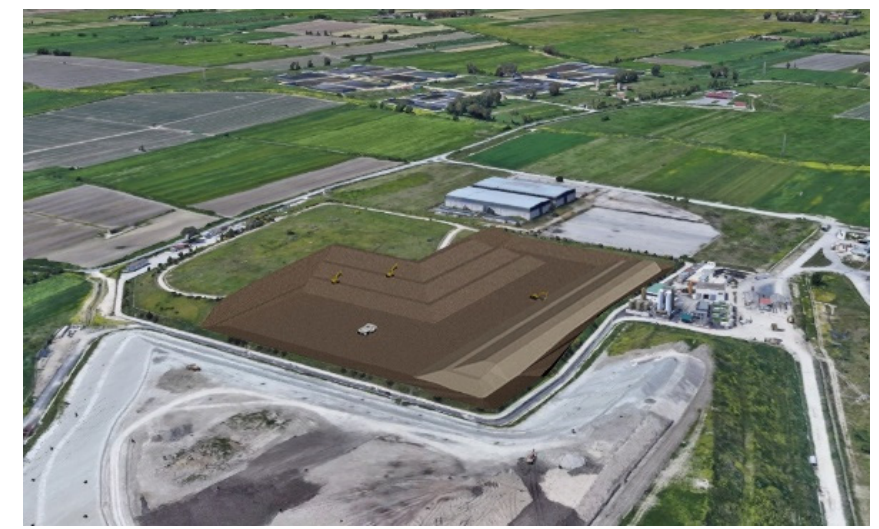

(b)

Figure 4: The area during the excavation operations. (a) Phase 1; and (b) Phase 2. 

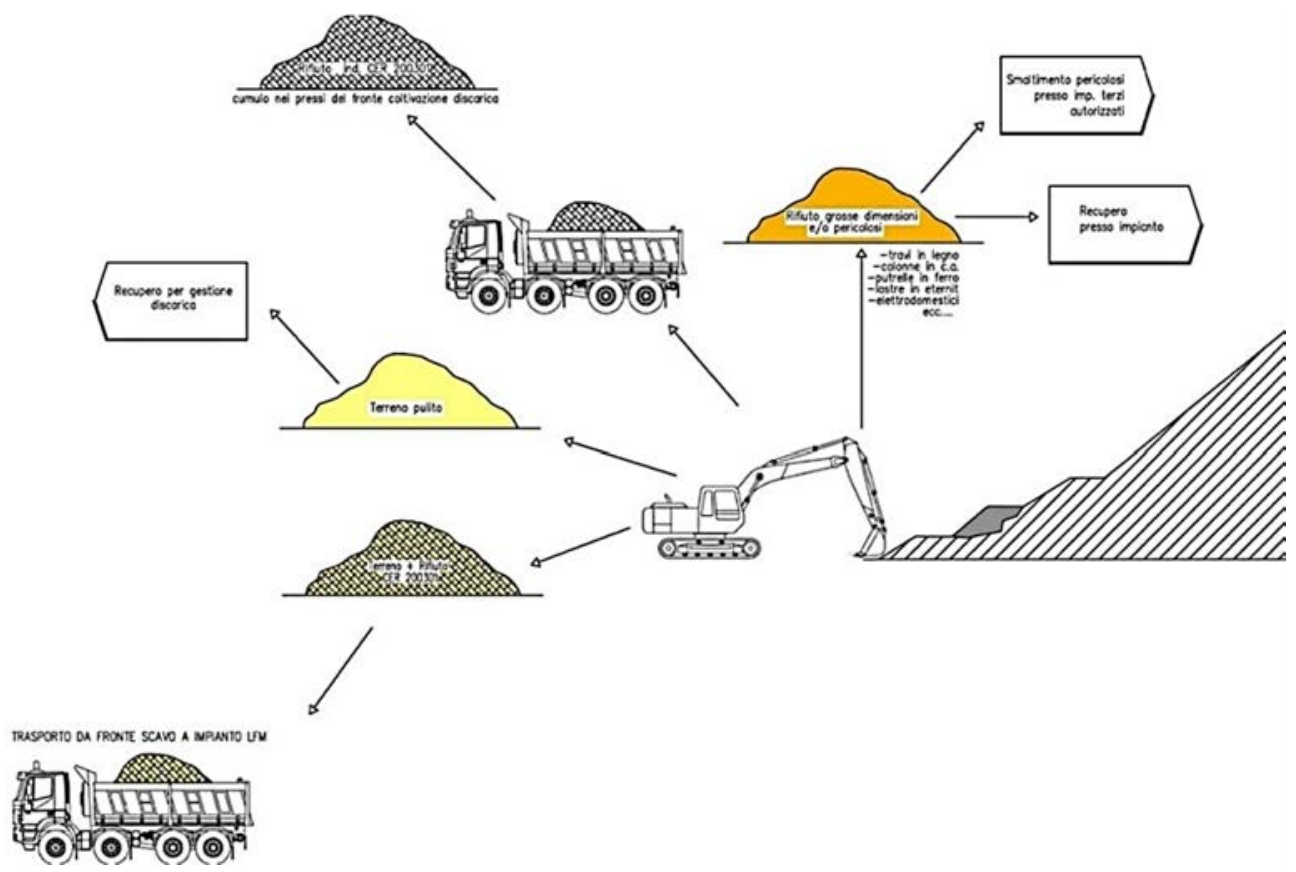

Figure 5: Work flows.

Operating phases: scraper by means of excavator, loading of the land on a transport vehicle. Once the soil is unloaded, leveling will be performed using a dozer/crawler loader.

Flow 2: Land and waste; Operating phases: loading by excavator on a vehicle, unloading near the screen, loading by means of an excavator equipped with an octopus inside the screening hopper.

Flow 3: Undifferentiated waste, it will be directly loaded by excavator on a vehicle and sent to the selection or stabilization plants for subsequent processing.

The excavated material, after having undergone a first visual check and a first screening, will be sent directly to the mobile plants present at the adjacent storage site and described in the following paragraphs, for the subsequent selection and recovery activities.

\subsection{Selection and/or stabilization}

The excavated material, freed from the cumbersome waste, will be started at a first selection, with a vibrating screen $20-30 \mathrm{~mm}$ holes, between waste and soil, positioned on the excavation front. The ground will be transported to the platforms 5, 6 or 7 for storage and reuse in the management of the new landfill. The survivor will be transported to the selection plant of the platform 3 or at the platform $3 \mathrm{c}$ in the event of stabilization (wetted waste).

The platform $3 \mathrm{a}$ will be equipped with a selection plant (TMB) for the recovery of the dry (CSS) and precious plastics, in addition to the recovery of ferrous and non-ferrous metals. The selection operations will be carried out inside two retractable and removable sheds. The third platform will also be equipped with two other sheds $(100 \times 26 \mathrm{~m})$ for the storage of fine waste. 
The selection of the waste will take place according to the following layout (Figs 6 and 7).

The waste stabilized or not, after a first screening carried out with mobile screen on the excavation face, undergoes the following treatment:

- Double shaft shredding;

- Vibrating sieving (three outputs) with holes 80 and $30 \mathrm{~mm}$;

- Aeraulic sieving;

- Metal deferry (ferrous, aluminum);

- $\quad$ Optical selection (PET, PVC, HDPE);

- Pressing.

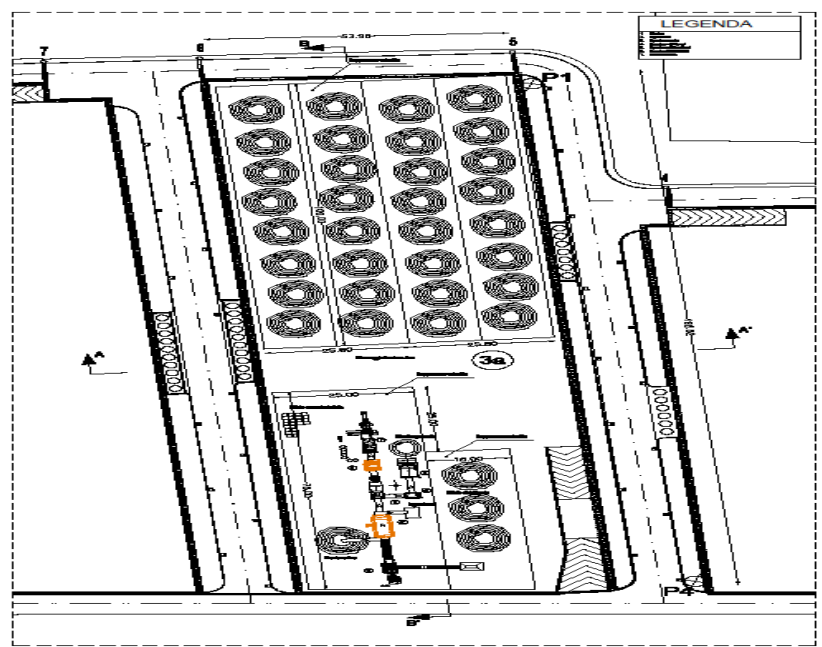

Figure 6: Platform 3a.

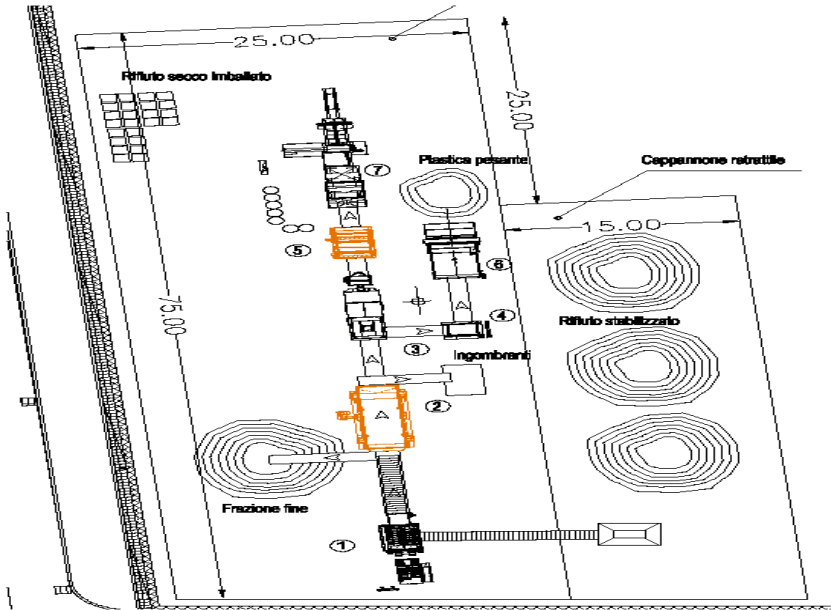

Figure 7: Selection plant layout. 


\subsection{Landfill reconfiguration}

Simultaneously with the excavation phases and the recovery and selection of excavated waste, the reconstruction of the two landfill sites will be carried out, respecting the volume, approximately 1,200,000 cubic meters, and the existing morphology [2], [5].

The interventions scheduled for the following operational phase are listed below:

a. Removal of the drainage system and leachate collection;

b. Reconstruction of the last waterproofing layer of the base barrier (HDPE, TNT, etc.);

c. Reconstruction of the draining system and collection of the leachate;

d. Landfill of waste (non-recoverable/waste from selection + stabilized ones coming from STIR of S. Maria CV);

e. Reconstruction of the biogas collection and management system;

f. Reconstruction of the landfill closure layer (capping).

\section{CONCLUSIONS}

The implementation of the planned activities will make it possible to use the pre-existing site without having to create a new landfill.

The development of the LFM project has made it possible to achieve some very important results:

- More than $70 \%$ of the soil contained in the old landfill was recovered and was reused on site to manage the coverings of the new one;

- More than $80 \%$ of inert materials deriving from construction and demolition has been recovered and started for re-use activities;

- Concerning solid urban waste, by using the new available technologies, plastic and metal fractions, were almost totally recovered and destined for recycling.

Then, the LFM project made it possible to recover new landfill volumes without building new ones and made it possible to recover a large part of the contents in the previous landfill and to allocate it to the recycling chain.

Finally, through the construction of the plants planned, the area will be able to host industrial companies of excellence in order to act on environmental impact connected with the presence of landfills by removing of the entire amount of waste and the subsequent inerting of dangerous fractions and by recovering materials present in the landfill with consequent obtaining of economic benefits.

\section{REFERENCES}

[1] Jones, P.T., Geysen, D., Tielemans, Y. \& Van Passel, S., Enhanced landfill mining in view of multiple resource recovery: A critical review. Journal of Cleaner, 2013.

[2] Bosmans, A., Vanderreydt, I. \& Geyse, D., The crucial role of waste-to-energy technologies in enhanced landfill mining: a technology review. Journal of Cleaner, 2013.

[3] Hogland, W., Marques, M. \& Nimmermark, S., Landfill mining and waste characterization: A strategy for remediation of contaminated areas. Journal of Material Cycles, 2004.

[4] Van der Zee, D.J., Achterkamp, M.C. \& De Visser, B.J., Assessing the market opportunities of landfill mining. Waste Management, 2004. 
[5] Kaartinen, T., Sormunen, K. \& Rintala, J., Case study on sampling, processing and characterization of landfilled municipal solid waste in the view of landfill mining. Journal of Cleaner Production, 2013.

[6] Hogland, W., Hogland, M. \& Marques, M., Enhanced landfill mining: Material recovery, energy utilisation and economics in the EU (Directive) perspective. Enhanced Landfill Mining, 2010.

[7] Danthurebandara, M., Van Passel, S. \& Vanderreydt, I., Assessment of environmental and economic feasibility of enhanced landfill mining. Waste Management, 2015. 